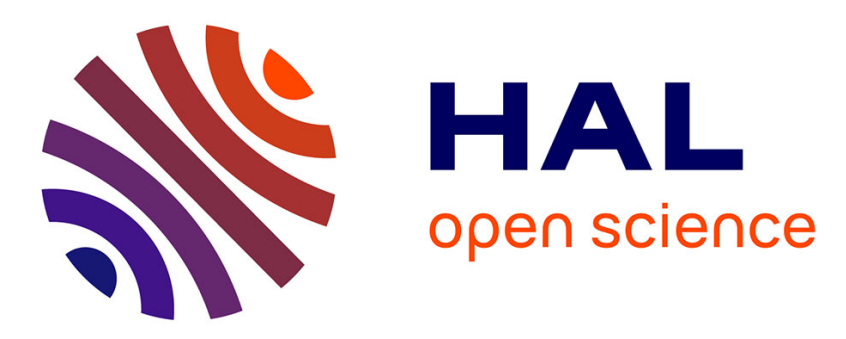

\title{
Enhanced density-based models for solid compound solubilities in supercritical carbon dioxide with cosolvents
}

Martial Sauceau, Jean-jacques Letourneau, Dominique Richon, Jacques Fages

\section{- To cite this version:}

Martial Sauceau, Jean-jacques Letourneau, Dominique Richon, Jacques Fages. Enhanced densitybased models for solid compound solubilities in supercritical carbon dioxide with cosolvents. Fluid Phase Equilibria, 2003, 208 (1-2), pp.99-113. 10.1016/S0378-3812(03)00005-0 . hal-01668425

\section{HAL Id: hal-01668425 \\ https://hal.science/hal-01668425}

Submitted on 15 Mar 2018

HAL is a multi-disciplinary open access archive for the deposit and dissemination of scientific research documents, whether they are published or not. The documents may come from teaching and research institutions in France or abroad, or from public or private research centers.
L'archive ouverte pluridisciplinaire HAL, est destinée au dépôt et à la diffusion de documents scientifiques de niveau recherche, publiés ou non, émanant des établissements d'enseignement et de recherche français ou étrangers, des laboratoires publics ou privés. 


\title{
Enhanced density-based models for solid compound solubilities in supercritical carbon dioxide with cosolvents
}

\author{
M. Sauceau ${ }^{\text {a }}$, J.-J. Letourneau a ${ }^{\text {, D. Richon }}{ }^{\text {b }}$, J. Fages ${ }^{\text {a }}{ }^{*}$ \\ ${ }^{a}$ Laboratoire de Génie des Procédés des Solides Divisés, UMR CNRS 2392, \\ École des Mines d'Albi-Carmaux, Albi 81013, France \\ b Laboratoire de Thermodynamique des Équilibres entre Phases/CENERG, \\ École des Mines de Paris, Fontainebleau 77305, France
}

\begin{abstract}
The ability to correlate and predict the solubility of solids in supercritical fluids is of the utmost importance for the design and the evaluation of supercritical processes. Previously, we have investigated the solubility of a pharmaceutically interesting solid compound in supercritical carbon dioxide, alone or mixed with cosolvents. In this work, these solubility data are correlated through several density-based semi-empirical models. These models have been either modified or extended to be applied to mixtures including a cosolvent. The validity of the resulting correlations is checked by using the solubility data of another pharmaceutical solid, naproxen.
\end{abstract}

Keywords: Solid-fluid equilibria; Solubility; Supercritical carbon dioxide; Cosolvent; Modeling

\section{Introduction}

Supercritical fluids (SCF) are widely used in many fields of application. The interest in using this technology is due to the special properties that are inherent to this class of fluids. This includes the ability to vary easily and over a large extent the solvent density, and to effect a drastic change in solvent properties by changing either the pressure or the temperature. The most common $\mathrm{SCF}$, carbon dioxide $\left(\mathrm{CO}_{2}\right)$, is easy to handle, inert, nontoxic, nonflammable, and has convenient critical coordinates. The applications often involve solutes that are in solid state at conditions where the solvent is in supercritical conditions. Thus, the knowledge of the solubility of solids in involved supercritical fluids is essential for evaluating the feasibility and for establishing optimum operating conditions.

\footnotetext{
* Corresponding author. Tel.: +33-5-6349-3141; fax: +33-5-6349-3025.

E-mail address: jacques.fages@enstimac.fr (J. Fages).
} 
Table 1

Experimental data for $\mathrm{PC}$ in supercritical $\mathrm{CO}_{2}$

\begin{tabular}{llllr}
\hline Cosolvent & Cosolvent mole fraction $y_{3}(\%)$ & Pressure $P(\mathrm{MPa})$ & Temperature $T(\mathrm{~K})$ & Number of data \\
\hline None & - & $9.9-29.70$ & 308.15 & 9 \\
None & - & $9.3-30.2$ & 318.15 & 11 \\
Ethanol & 5 & $9.8-30.4$ & 318.15 & 11 \\
Ethanol & $4.0-17.1$ & 20 & 318.15 & 6 \\
DMSO & 2 & $12.2-29.1$ & 318.15 & 6 \\
DMSO & $0.9-3.3$ & 20 & 318.15 & 7 \\
\hline
\end{tabular}

All the data from [1].

Because of the limited amount of experimental data dealing with solid-SCF systems, there is considerable interest in mathematical models that can accurately predict the phase behavior of such systems. Some of the commonly used models that have been used with some success to correlate solid solubility data include equations of state (EoS). However, such models often require properties (such as critical temperature, critical pressure and acentric factor) that are not available for most of solid solutes. Also, the models require one or more temperature-dependent parameters, which must be obtained from solid solubility data in pure fluids. For these reasons, EoS based models cannot be easily used to predict solubilities. Several authors have noticed that the logarithm of solid compound solubilities is approximately a linear function of the SCF density. This observation allows the representation of the solubility by using semi-empirical models, based on density instead of pressure. These relations are very useful because the knowledge of the above mentioned physical properties is not necessary.

In a previous paper, the solubility of a pharmaceutical compound, called PC, was investigated [1] by means of an apparatus based on an open circuit method [2]. The solubility was measured in pure supercritical $\mathrm{CO}_{2}$ and in supercritical $\mathrm{CO}_{2}$ mixtures with ethanol and dimethylsulfoxide (DMSO) (Table 1). In this work, these experimental equilibrium solubilities are correlated using three different models, developed and extended to be applicable to solvent-cosolvent mixtures.

\section{Data correlation}

The first model was proposed by Chrastil [3]. This may be considered as a macroscopic description of the surroundings of the molecules in the fluid phase. It is based on the hypothesis that one molecule of a solute A associates with $k$ molecules of a solvent $\mathrm{B}$ to form one molecule of a solvato-complex $\mathrm{AB}_{k}$ in equilibrium with the system. The definition of the equilibrium constant through thermodynamic considerations leads to the following expression for the solubility:

$$
\ln \left(C_{2}\right)=k \ln \left(\rho_{\mathrm{f}}\right)+\frac{\alpha}{T}+\beta
$$

where $C_{2}$ is the concentration of the solute in the supercritical phase, $\rho_{\mathrm{f}}$ the density of the fluid phase, $k$ the association number, $\alpha$ depends on the heat of solvation and the heat of vaporization of the solute and $\beta$ depends on the molecular weight of the species. Parameters $k, \alpha$ and $\beta$ are adjusted to solubility experimental data.

The second model was developed by Ziger and Eckert [4], partly on the basis of the regular solution theory and the van der Waals equation of state (vdW EoS). In this treatment, the vdW EoS and mixing 
rules are used to evaluate the fugacity coefficient of the solute in the SCF phase in terms of solubility parameters of the solute and the solvent. The Hildebrand solubility parameter, $\delta$, is an indicator of the strength of intermolecular forces present in a solute or solvent and is defined as the square root of the cohesive energy density. The final expression for the semi-empirical correlation derived by Ziger and Eckert [4] is represented by the following equation:

$$
\log _{10} E=\eta_{1}\left[\varepsilon_{2} \frac{\Delta}{y_{1}}\left(2-\frac{\Delta}{y_{1}}\right)-\log _{10}\left(1+\left(\frac{\delta_{1}^{2}}{P}\right)\right)\right]+v_{1}
$$

where

$$
E=\frac{y_{2} P}{P_{2}^{\text {sat }}}, \quad \varepsilon_{2}=\frac{\left(\delta_{2}\right)^{2} v_{2}^{\mathrm{L}}}{2.3 R T} \quad \text { and } \quad \Delta=\frac{\delta_{1}}{\delta_{2}}
$$

where $y_{i}$ is the equilibrium mole fraction of the compound $i$ in the SCF phase, $P$ the total pressure, $P_{2}^{\text {sat }}$ the sublimation pressure of the solute, $\delta_{i}$ the solubility parameter of the compound $i, R$ the ideal gas constant and $v_{2}^{\mathrm{L}}$ the molar volume of the solute in liquid state. $E$ is the enhancement factor defined as the ratio between the observed equilibrium solubility and that predicted by the ideal gas law at the same temperature and pressure, $\varepsilon_{2}$ represents a dimensionless energy parameter and $\Delta$ is the ratio of solubility parameters for solvent and solute. Parameters $\eta_{1}$ and $v_{1}$ represent constants obtained by regression of the experimental data that are characteristics of each solvent and solute, respectively.

The third model is based on the theory of dilute solutions, which leads to simple expressions for many thermodynamic properties of dilute near-critical binary mixtures. In particular, Harvey [5] has obtained a simple linear relationship for the solubility of a solid in a supercritical solvent. Mendez-Santiago and Teja [6] have approximated this relationship by

$$
T \ln E=A_{1}+B_{1} \rho_{\mathrm{f}}
$$

where $A_{1}$ and $B_{1}$ are adjustable parameters. They have also incorporated a Clausius-Clapeyron type equation for the sublimation pressure and obtained a new correlation with three adjustable parameters $A_{1}^{\prime}, B_{1}^{\prime}$ and $C_{1}^{\prime}[6]$ :

$$
T \ln y_{2} P=A_{1}^{\prime}+B_{1}^{\prime} \rho_{\mathrm{f}}+C_{1}^{\prime} T .
$$

However, the Clausius-Clapeyron equation could be advantageously written with the dimensionless logarithm:

$$
\ln \frac{P_{2}^{\mathrm{sat}}}{P^{\mathrm{std}}}=i-\frac{j}{T}
$$

where $P^{\text {std }}$ is the standard pressure (atmospheric pressure equal to $0.101325 \mathrm{MPa}$ ). This provides the following correlation with three adjustable parameters $A_{2}, B_{2}$ and $C_{2}$ :

$$
T \ln \frac{y_{2} P}{P^{\text {std }}}=A_{2}+B_{2} \rho_{\mathrm{f}}+C_{2} T .
$$

Finally, in another paper, the same authors [7] have improved the Eq. (4) by taking into account the cosolvent mole fraction, $y_{3}$ :

$$
T \ln E=A_{3}+B_{3} \rho_{\mathrm{f}}+D_{3} y_{3}
$$

where $A_{3}, B_{3}$ and $D_{3}$ are three new adjustable parameters. 


\section{Results and discussion}

\subsection{Density calculations}

The three correlations require the knowledge of supercritical mixture densities. As the pharmaceutical compound solubility is extremely low, the density change due to the presence of the solid compound is negligible and then it is neglected. As a consequence, the density of the saturated supercritical phase is taken equal to the density of the solvent $\left(\mathrm{CO}_{2}\right.$ or $\mathrm{CO}_{2}+$ cosolvent). The pure $\mathrm{CO}_{2}$ density is calculated by using the Peng-Robinson equation of state [8] (PR EoS). For the mixtures involving a cosolvent, the density is calculated by using the PR EoS [8], with two quadratic mixing rules and two binary interaction parameters, $k_{i j}$ and $l_{i j}$ (Table 2), from works of Kordikowski et al. [9] and of Ting et al. [10].

The quality of all data correlations is quantified by the average absolute deviation (AAD), defined as follows:

$$
\mathrm{AAD}=\frac{1}{n} \sum_{i=1}^{n}\left|\frac{y_{2, \mathrm{cal}}-y_{2, \exp }}{y_{2, \exp }}\right|_{i} \times 100
$$

where $n$ is the number of data, $y_{2, \text { cal }}$ the calculated solubility value and $y_{2, \text { exp }}$ the experimental one.

\subsection{Extension of the Chrastil model}

The Eq. (1) is first applied to solubility data of the pharmaceutical solid PC in pure $\mathrm{CO}_{2}$. The two isotherms are well fitted (lines 1 and 2 of Table 3), the AAD being less than $8 \%$. The $k$ value obtained shows small temperature dependence. If the data of the two isotherms are gathered before parameter adjustment, the AAD remains practically constant (line 3).

The Chrastil model is applicable to pure fluids. Thus, we could apply it to mixtures at constant cosolvent mole fractions, with the hypothesis that these mixtures at constant concentration behave like pure fluids. The results are listed in Table 3 (lines 4 and 5). The data are well correlated with an AAD less than 6\%. The same treatment can be made as for the Chrastil model, with the assumption that one molecule of a solute $\mathrm{A}$ associates with $k_{1}$ molecules of a solvent $\mathrm{B}$ and $k_{3}$ molecules of a cosolvent $\mathrm{C}$ to form one molecule of a solvato-complex $\mathrm{AB}_{k_{1}} \mathrm{C}_{k_{3}}$. Finally, the Eq. (1) becomes:

$$
\ln \left(C_{2}\right)=\left(k_{1}+k_{3}\right) \ln \left(\rho_{\mathrm{f}}\right)+\frac{\alpha}{T}+\beta
$$

Table 2

Cosolvent critical properties and binary interaction parameters with $\mathrm{CO}_{2}$

\begin{tabular}{lllllr}
\hline Cosolvent & $T_{\mathrm{C}}(\mathrm{K})$ & $P_{\mathrm{C}}(\mathrm{MPa})$ & $\omega$ & $k_{i j}$ & $l_{i j}$ \\
\hline DMSO $^{\mathrm{a}}$ & 720.0 & 5.705 & 0.350 & 0.015 & -0.025 \\
Ethanol $^{\mathrm{a}}$ & 516.2 & 6.384 & 0.635 & 0.089 & 0.000 \\
Ethyl acetate $^{\mathrm{a}}$ & 523.0 & 3.83 & 0.362 & -0.02 & 0.010 \\
Acetone $^{\mathrm{b}}$ & 508.2 & 4.66 & 0.318 & 0.0137 & 0.000 \\
Methanol $^{\mathrm{b}}$ & 512.6 & 8.09 & 0.556 & 0.0749 & 0.000 \\
\hline
\end{tabular}

\footnotetext{
${ }^{a}$ Data from [9].
}

${ }^{\mathrm{b}}$ Data from [10]. 
Table 3

Correlation of PC solubility data with Eq. (1)

\begin{tabular}{llccccc}
\hline Cosolvent & $T(\mathrm{~K})$ & Data & \multicolumn{2}{c}{ Eq. $(1)$} & & \\
\cline { 5 - 7 } & & & $k$ & $\alpha\left(\times 10^{3} \mathrm{~K}\right)$ & $\beta$ & AAD $(\%)^{\mathrm{a}}$ \\
\hline None & 308.15 & 9 & 7.11 & -6.92 & -31.26 & 6.2 \\
None & 318.15 & 11 & 6.44 & -7.97 & -23.06 & 7.1 \\
None & All & 20 & 6.55 & -10.89 & -14.62 & 7.7 \\
Ethanol: $5 \%$ & 318.15 & 11 & 7.18 & -28.92 & -39.53 & 5.9 \\
DMSO: $2 \%$ & 318.15 & 6 & 10.13 & -7.24 & -47.34 & 4.7 \\
\hline
\end{tabular}

${ }^{\text {a }}$ Defined in Eq. (9).

The values of $k$ obtained in Table 3 are thus the number of molecules of solvent $k_{1}$ and cosolvent $k_{3}$ associated with one molecule of solute. These numbers are higher than that in pure $\mathrm{CO}_{2}: 7.2$ with $5 \%$ of ethanol and 10.1 with $2 \%$ of DMSO instead of 6.5 in pure $\mathrm{CO}_{2}$. This confirms the importance of specific interactions in the solubility enhancement phenomenon [1].

\subsection{New correlation using a modified Ziger and Eckert model}

Applying the Ziger and Eckert model requires the estimation of the thermodynamic properties of pure components, for both the solvent and the solute. As noted by Giddings et al. according to the vdW theory [11], the solubility parameter of the pure SCF can be written as follows:

$$
\delta_{1}=\frac{\left(a_{1}\right)^{1 / 2} \rho_{1}}{M_{1}}
$$

where $M_{1}$ is the solvent molecular weight and $a_{1}$ the energy parameter of the solvent in vdW equation, calculated by

$$
a_{1}=\frac{27}{64} \frac{R^{2} T_{\mathrm{C}}^{2}}{P_{\mathrm{C}}} .
$$

Ziger and Eckert [4] consider the solid solute as a subcooled liquid and hence evaluate all the solute parameters after extrapolation of liquid properties from the melting point using a thermal coefficient. Gurdial and Foster [12] suggested that thermodynamic properties could be estimated more readily from an atomic and group contribution method as proposed by Fedors [13]. This atomic and group contribution method, which requires only the knowledge of the structural formula of the compound, is applicable not only to linear compounds but also to organometallic and cyclic compounds at $298.15 \mathrm{~K}$. In the case of a cyclic compound, this is accomplished by adding cyclization increments to both the energy of vaporization and the molar volume of a linear compound having the same chemical structure as the cyclic compound of interest. Fedors [13] has also proposed relationships to take into account the temperature influence on both the molar volume and the solubility parameter for low temperature variations $(<50 \mathrm{~K})$. This approach was adopted for the evaluation of the solubility parameter and molar volume of our solid compound. However, due to the lack of experimental data, the thermal expansion coefficient for our solute was assumed to be similar to the value for naphthalene $\left(0.0007 \mathrm{~K}^{-1}\right)$ [12]. The values obtained are listed in Table 4 . 
Estimation of solubility parameters and molar volumes of solids compounds

\begin{tabular}{|c|c|c|c|c|c|c|}
\hline & \multicolumn{6}{|c|}{ Compound } \\
\hline & \multicolumn{3}{|l|}{$\mathrm{PC}$} & \multicolumn{3}{|c|}{ Naproxen } \\
\hline & $298.15 \mathrm{~K}$ & $308.15 \mathrm{~K}$ & $318.15 \mathrm{~K}$ & $313.1 \mathrm{~K}$ & $323.1 \mathrm{~K}$ & $323.1 \mathrm{~K}$ \\
\hline$\nu_{2}^{\mathrm{L}}\left(\mathrm{cm}^{3} \mathrm{~mol}^{-1}\right)^{\mathrm{a}}$ & 414.2 & 417.1 & 420.0 & 177.9 & 179.2 & 180.4 \\
\hline$\delta_{2}\left(\mathrm{MPa}^{1 / 2}\right)^{\mathrm{a}}$ & 22.5 & 22.3 & 22.2 & 23.4 & 23.2 & 23.1 \\
\hline
\end{tabular}

${ }^{a}$ Estimated by the method proposed by Fedors [13].

The Ziger and Eckert model requires also the knowledge of the saturated vapor pressure of the solute, $P_{2}^{\text {sat }}$, for calculating the enhancement factor, $E$. As this pressure is unknown for the solid $\mathrm{PC}, P_{2}^{\text {sat }}$ is replaced by a Clausius-Clapeyron equation, as Eq. (6). An improved correlation, with three adjustable parameters $\eta_{2}, \kappa_{2}$ and $\nu_{2}$, is thus obtained:

$$
\log _{10}\left(\frac{y_{2} P}{P^{\text {std }}}\right)=\eta_{2}\left[\varepsilon_{2} \frac{\Delta}{y_{1}}\left(2-\frac{\Delta}{y_{1}}\right)-\log _{10}\left(1+\left(\frac{\delta_{1}^{2}}{P}\right)\right)\right]+\frac{\kappa_{2}}{T}+v_{2} .
$$

Eq. (13) is valid for pure fluids. Thus, it has been modified to be applicable to cosolvent mixtures with a constant cosolvent mole fraction. The new expression is

$$
\log _{10}\left(\frac{y_{2} P}{P^{\mathrm{std}}}\right)=\eta_{3}\left[\varepsilon_{2} \frac{\Delta}{1-y_{2}}\left(2-\frac{\Delta}{1-y_{2}}\right)-\log _{10}\left(1+\left(\frac{\delta_{\mathrm{m}}^{2}}{P}\right)\right)\right]+\frac{\kappa_{3}}{T}+v_{3}
$$

with

$$
\delta_{\mathrm{m}}=\frac{\left(a_{\mathrm{m}}\right)^{1 / 2} \rho_{\mathrm{f}}}{y_{1} M_{1}+y_{3} M_{3}}
$$

where $\delta_{\mathrm{m}}$ is the solubility parameter of the solvent-cosolvent mixture. It depends on the mole fraction $y_{i}$ and the molecular weight $M_{i}$ of the pure compound $i$, and also on the density $\rho_{\mathrm{f}}$ and the energy parameter in vdW equation $a_{\mathrm{m}}$ of the solvent-cosolvent mixture. Parameter $a_{\mathrm{m}}$ is calculated from pure component parameters by using a quadratic mixing rule:

$$
a_{\mathrm{m}}=\sum_{i} \sum_{i} y_{i} y_{j} a_{i j} \quad \text { with } \quad a_{i j}=\sqrt{a_{i i} a_{j j}}\left(1-k_{i j}\right) \quad \text { and } \quad a_{i i}=a_{i}
$$

where $k_{i j}$ is a binary interaction parameter, already used before (Table 2). If no cosolvent is used, $\delta_{\mathrm{m}}$ is equal to $\delta_{1}$, its value in pure $\mathrm{CO}_{2}$, and Eqs. (13) and (14) are identical. Results for this equation are listed in Table 5. The two isotherms of solubility in pure $\mathrm{CO}_{2}$ are well fitted by Eq. (14) (lines 1 and 2), the AAD being less than $13 \%$. As for the $k$ value in Chrastil model, the $\eta_{3}$ value obtained shows small temperature dependence. If the two isotherms are gathered before parameter adjustment, the AAD remains practically constant (line 3). For mixtures with a constant cosolvent mole fraction, a good correlation is obtained with an AAD less than 7\% (lines 4 and 5). The parameter $\eta_{3}$, characteristic of the solvent [4], is increased in presence of cosolvent: from 0.20 for pure $\mathrm{CO}_{2}$ to 0.24 with a $5 \%$ ethanol mole fraction and to 0.31 with a $2 \%$ DMSO mole fraction. This confirms that the mixtures at constant concentration behave like pure fluids, with, however, a better solvent power than pure $\mathrm{CO}_{2}$. 
Table 5

Correlation of PC solubility data with Eq. (14)

\begin{tabular}{|c|c|c|c|c|c|c|}
\hline \multirow[t]{2}{*}{ Cosolvent } & \multirow[t]{2}{*}{$T(\mathrm{~K})$} & \multirow[t]{2}{*}{ Number of data } & \multicolumn{4}{|c|}{ Eq. (14) } \\
\hline & & & $\eta_{3}$ & $\kappa_{3}(\mathrm{~K})$ & $v_{3}$ & $\operatorname{AAD}(\%)^{\mathrm{a}}$ \\
\hline None & 308.15 & 9 & 0.22 & -2.06 & -3.23 & 12.6 \\
\hline None & 318.15 & 11 & 0.19 & 5.12 & -24.65 & 9.9 \\
\hline None & All & 20 & 0.20 & -7.36 & 14.45 & 11.1 \\
\hline Ethanol: $5 \%$ & 318.15 & 11 & 0.24 & -1.06 & -5.56 & 7.1 \\
\hline DMSO: $2 \%$ & 318.15 & 6 & 0.31 & -3.65 & 1.16 & 4.3 \\
\hline
\end{tabular}

a Defined in Eq. (9).

However, this correlation cannot represent the variation of the cosolvent mole fraction. As can be seen on Fig. $1, \log _{10}\left(y_{2} P / P^{\text {std }}\right)$ shows a linear dependence with $\log _{10}\left(y_{3}\right)$ at a given temperature. This observation leads to adding an additional term in Eq. (14), as follows:

$$
\log _{10}\left(\frac{y_{2} P}{P^{\mathrm{std}}}\right)=\eta_{4}\left[\varepsilon_{2} \frac{\Delta}{1-y_{2}}\left(2-\frac{\Delta}{1-y_{2}}\right)-\log _{10}\left(1+\left(\frac{\delta_{\mathrm{m}}^{2}}{P}\right)\right)\right]+\frac{\kappa_{4}}{T}+\lambda_{4} \log _{10} y_{3}+v_{4} .
$$

This new relationship has four adjustable parameters: $\eta_{4}, \kappa_{4}, \lambda_{4}$ and $\nu_{4}$. As can be seen in the first two lines of Table 6, good results are obtained when applying Eq. (17) to mixtures with ethanol or DMSO. As solubility data with a cosolvent are available at only one temperature, correlation is carried out with the constant relative to temperature, $\kappa_{4}$, equal to that obtained for all temperatures in pure supercritical $\mathrm{CO}_{2}, \kappa_{3}$ (third line of Table 5). This modification involves no change in values of $\eta_{4}$ and $\lambda_{4}$ (two last lines in Table 6). As already observed by Ziger and Eckert [4], $\eta_{4}$ and $v_{4}$ are constants for each solvent and solute, respectively. Thus, $\eta_{4}$ is different for each solvent-cosolvent mixture, while $v_{4}$ remains constant.

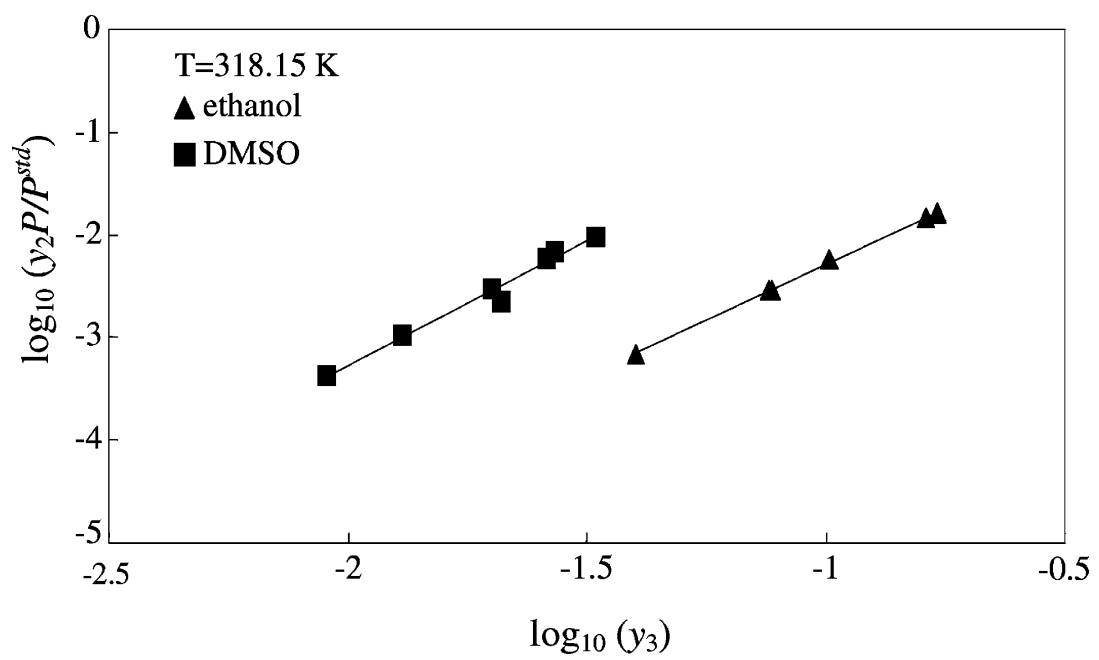

Fig. $1 . \log _{10}\left(y_{2} P / P^{\text {std }}\right)$ vs. $\log _{10}\left(y_{3}\right)$ for PC solubility data with a cosolvent at $318.15 \mathrm{~K}$. 
Table 6

Correlation of PC solubility data with Eq. (17)

\begin{tabular}{lllrlrl}
\hline Cosolvent & Number of data & \multicolumn{2}{l}{ Eq. $(17)$} & & & \\
\cline { 3 - 7 } & & $\eta_{4}$ & $\kappa_{4}(\mathrm{~K})$ & $\lambda_{4}$ & $v_{4}$ & AAD $(\%)^{\mathrm{a}}$ \\
\hline Ethanol & 17 & 0.24 & -0.63 & 1.71 & -4.71 & 6.6 \\
DMSO & 13 & 0.31 & 0.80 & 2.17 & -9.04 & 9.0 \\
Ethanol & 17 & 0.24 & -7.36 & 1.71 & 16.43 & 6.6 \\
DMSO & 13 & 0.31 & -7.36 & 2.17 & 16.58 & 9.0
\end{tabular}

${ }^{\text {a }}$ Defined in Eq. (9).

$\kappa_{4}$ is fixed by pure $\mathrm{CO}_{2}$ data and thus is the same for the two cosolvents. The higher increase of cosolvent effect with cosolvent mole fraction for DMSO is expressed by the higher value of $\lambda_{4}$.

\subsection{Generalizing the Mendez-Santiago and Teja model}

Eq. (7) has directly been applied to all data in pure $\mathrm{CO}_{2}$ as it takes into account the temperature. It provides a good correlation, with an AAD about 6\% (first line in Table 7).

As already done by Mendez-Santiago and Teja in Eq. (5), a Clausius-Clapeyron-type equation (Eq. (6)) is incorporated for the sublimation pressure in Eq. (8) to give the new correlation, with four adjustable parameters:

$$
T \ln \left(\frac{y_{2} P}{P^{\text {std }}}\right)=A_{4}+B_{4} \rho_{\mathrm{f}}+C_{4} T+D_{4} y_{3} .
$$

Results for this correlation are presented in Table 7. In a first attempt, solubility data are treated independently for each cosolvent, by gathering data at different pressures and cosolvent mole fractions. The two data at higher ethanol mole fractions (16.2 and 17.1\%) are ignored because they provoke a large increase in the AAD. Data are well fitted, with an AAD about $6 \%$ for ethanol (line 2) and about 19\% for DMSO (line 3). AAD for DMSO is larger probably because there are more data at different mole fraction values

Table 7

Correlation of PC solubility data with Eqs. (7), (18) and (19)

\begin{tabular}{|c|c|c|c|c|c|c|}
\hline \multirow[t]{2}{*}{ Cosolvent } & \multirow[t]{2}{*}{ Number of data } & \multicolumn{5}{|l|}{ Eq. (18) } \\
\hline & & $A_{4}(\mathrm{~K})$ & $B_{4}\left(\mathrm{~K} \mathrm{~m}^{3} \mathrm{~kg}^{-1}\right)$ & $C_{4}$ & $D_{4}(\mathrm{~K})$ & $\operatorname{AAD}(\%)^{\mathrm{a}}$ \\
\hline- & 20 & $-16.24^{\mathrm{b}}$ & $3.53^{\mathrm{c}}$ & $33.35^{\mathrm{d}}$ & - & 6.4 \\
\hline Ethanol & 15 & -6.42 & 3.84 & 1.89 & 8.57 & 6.4 \\
\hline DMSO & 13 & -4.61 & 4.85 & -6.26 & 34.13 & 19.1 \\
\hline Ethanol & 35 & -16.63 & 3.59 & 34.45 & 9.40 & 7.7 \\
\hline DMSO & 33 & -16.93 & 3.63 & 35.30 & 38.90 & 14.8 \\
\hline All & 48 & $-17.16^{\mathrm{e}}$ & $3.67^{\mathrm{f}}$ & $35.96^{\mathrm{g}}$ & $\begin{array}{r}9.16^{\mathrm{h}} \\
38.59^{\mathrm{I}}\end{array}$ & 12.7 \\
\hline
\end{tabular}

${ }^{\text {a }}$ Defined in Eq. (9). ${ }^{\mathrm{b}, \mathrm{c}, \mathrm{d}}$ coefficients $A_{2}, B_{2}$ and $C_{2}$, respectively, from Eq. (7); ${ }^{\text {e,f,g,h,i }}$ coefficients $A_{5}, B_{5}, C_{5}, D_{5}$ and $E_{5}$, respectively, from Eq. (19). 
(7 instead of 4). However, data are available at only one temperature, which is not enough to determine correctly the value of the parameter, $C_{4}$, related to temperature. In order to have data at two different temperatures, a second correlation is carried out by gathering data for each cosolvent with that in pure $\mathrm{CO}_{2}$ (lines 4 and 5). Finally, the AAD remains constant at about $8 \%$ for ethanol and decreased from 19 to $15 \%$ for DMSO, with coefficients attributed to density, $B_{4}$, and to temperature, $C_{4}$, close to those obtained in pure $\mathrm{CO}_{2}$. It shows that these two coefficients can be considered to be independent of the presence of a cosolvent. It has also to be noted that the value obtained for the coefficient $A_{4}$ remains practically constant in $\mathrm{CO}_{2}$ alone and with a cosolvent. The part of cosolvent effect due to specific interactions between solute and cosolvent is thus independent of density and temperature effects, and is quantified by the value of cosolvent mole fraction coefficient, $D_{4}$. On the basis of these observations, a correlation of all PC solubility data can be carried out by using the following equation with five adjustable parameters:

$$
T \ln \left(\frac{y_{2} P}{P^{\text {std }}}\right)=A_{5}+B_{5} \rho_{\mathrm{f}}+C_{5} T+D_{5} y_{3}^{\text {ethanol }}+E_{5} y_{3}^{\text {DMSO }} .
$$

The data in pure $\mathrm{CO}_{2}$ are treated with: $y_{3}^{\text {ethanol }}=y_{3}^{\text {DMSO }}=0$, and the ones with a cosolvent with: $y_{3}^{\text {DMSO }}=0$ for ethanol as cosolvent and $y_{3}^{\text {ethanol }}=0$ for DMSO as cosolvent. All the data are finally correlated with a value of the AAD less than $13 \%$ (last line in Table 7). This correlation characterizes the solubility of the solid studied in supercritical $\mathrm{CO}_{2}$ by using only one equation: effects of density, of temperature and of each cosolvent are quantified by means of constant values. As previously noted, the effect due to DMSO ( $E_{5}$ at about 38,600$)$ is higher than that of ethanol $\left(D_{5}\right.$ at about 9200$)$. By plotting $T \ln \left(y_{2} P / P^{\text {std }}\right)-C_{5} T-D_{5} y_{3}^{\text {ethanol }}-E_{5} y_{3}^{\text {DMSO }}$ versus $\rho_{\mathrm{f}}$, all solubility data are gathered on a single line (Fig. 2).

\subsection{Validation with naproxen}

In order to expand the validity of the new correlations proposed in this work, they have been applied to the data of another pharmaceutical compound. We have chosen naproxen, because data are available, not only in pure $\mathrm{CO}_{2}$, but also with several cosolvents [10]. The data used in this work are listed in Table 8.

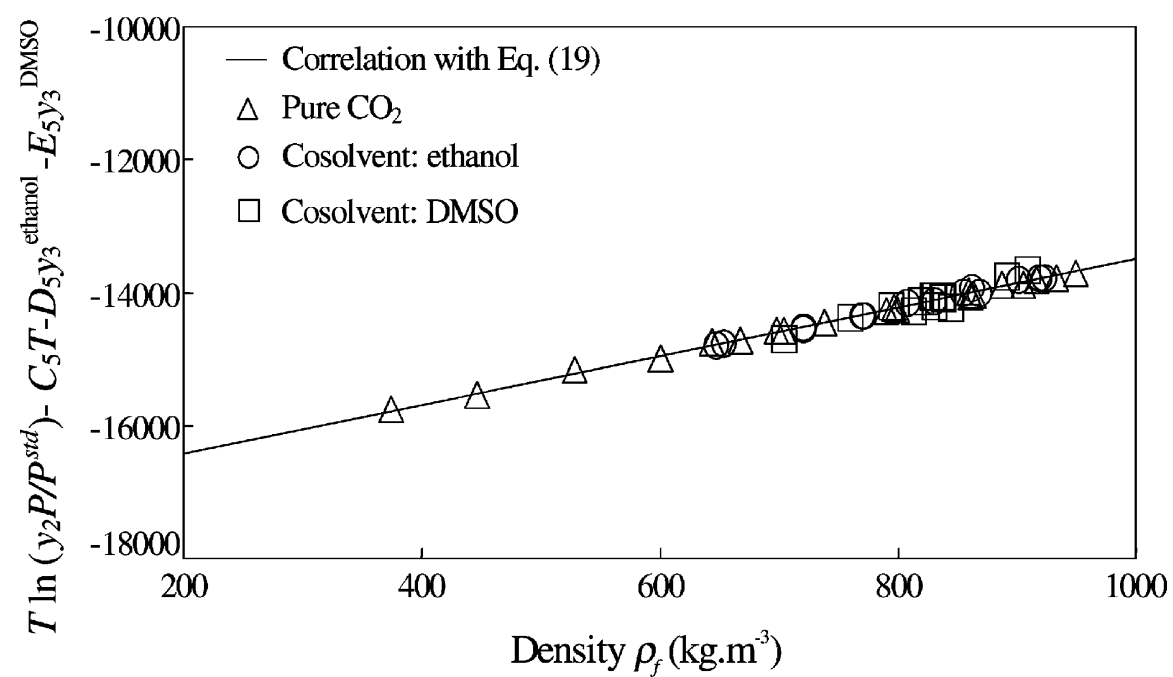

Fig. 2. $T \ln \left(y_{2} P / P^{\text {std }}\right)-C_{5} T-D_{5} y_{3}^{\text {ethanol }}-E_{5} y_{3}^{\text {DMSO }}$ vs. $\rho_{\mathrm{f}}$ : PC experimental solubility data and correlation with Eq. (19). 
Table 8

Experimental data of naproxen in supercritical $\mathrm{CO}_{2}$

\begin{tabular}{lllll}
\hline Cosolvent & Number of data & Pressure $P(\mathrm{MPa})$ & Temperature $T(\mathrm{~K})$ & Cosolvent mole fraction $y_{3}(\%)$ \\
\hline- & 18 & $9-17.9$ & $313.1,323.1,333.1$ & - \\
Ethanol & 24 & $11-17.9$ & $323.1,333.1$ & $1.75,3.5,5.25$ \\
Ethyl acetate & 18 & $11-17.9$ & 333.1 & $1.75,3.5,5.25$ \\
Acetone & 33 & $11-19.3$ & $313.1,323.1,333.1$ & $1.75,3.5,5.25$ \\
Methanol & 26 & $11-19.3$ & $323.1,333.1$ & $1.75,3.5,5.25$ \\
\hline
\end{tabular}

Table 9

Correlation of naproxen solubility data with Eq. (17)

\begin{tabular}{|c|c|c|c|c|c|c|}
\hline \multirow[t]{2}{*}{ Cosolvent } & \multirow[t]{2}{*}{ Number of data } & \multicolumn{5}{|c|}{ Eq. (17) } \\
\hline & & $\eta_{4}$ & $\kappa_{4}(\mathrm{~K})$ & $\lambda_{4}$ & $v_{4}$ & $\operatorname{AAD}(\%)^{\mathrm{a}}$ \\
\hline- & 18 & $0.33^{\mathrm{b}}$ & $-4.20^{\mathrm{c}}$ & - & $7.47^{\mathrm{d}}$ & 4.2 \\
\hline Ethanol & 24 & 0.33 & -4.66 & 1.23 & 11.47 & 2.8 \\
\hline Ethyl acetate & 18 & 0.36 & -0.27 & 0.69 & -3.25 & 3.6 \\
\hline Acetone & 33 & 0.33 & -4.10 & 0.77 & 8.69 & 7.2 \\
\hline Methanol & 26 & 0.35 & -3.95 & 1.16 & 8.94 & 5.8 \\
\hline
\end{tabular}

${ }^{a}$ Defined in Eq. (9). ${ }^{\text {b,c,d }}$ coefficients $\eta_{2}, \kappa_{2}, v_{2}$, respectively, from Eq. (13).

The first model applied is the Eq. (17). As for PC, the thermal expansivity of naproxen was assumed to be similar to that of naphthalene. The molar volumes and solubility parameters obtained for naproxen are listed in Table 4. Good correlation of data in pure $\mathrm{CO}_{2}$ is obtained with an AAD less than 5\%. (first line in Table 9). If a cosolvent is used, an important point for the applicability of Eq. (17) is the isothermal linear dependence of $\log _{10}\left(y_{2} P / P^{\text {std }}\right)$ versus $\log _{10}\left(y_{3}\right)$. This assumption is confirmed for all cosolvents and illustrated on Fig. 3 in the case of ethanol at $333.1 \mathrm{~K}$. Finally, the application of this relationship to

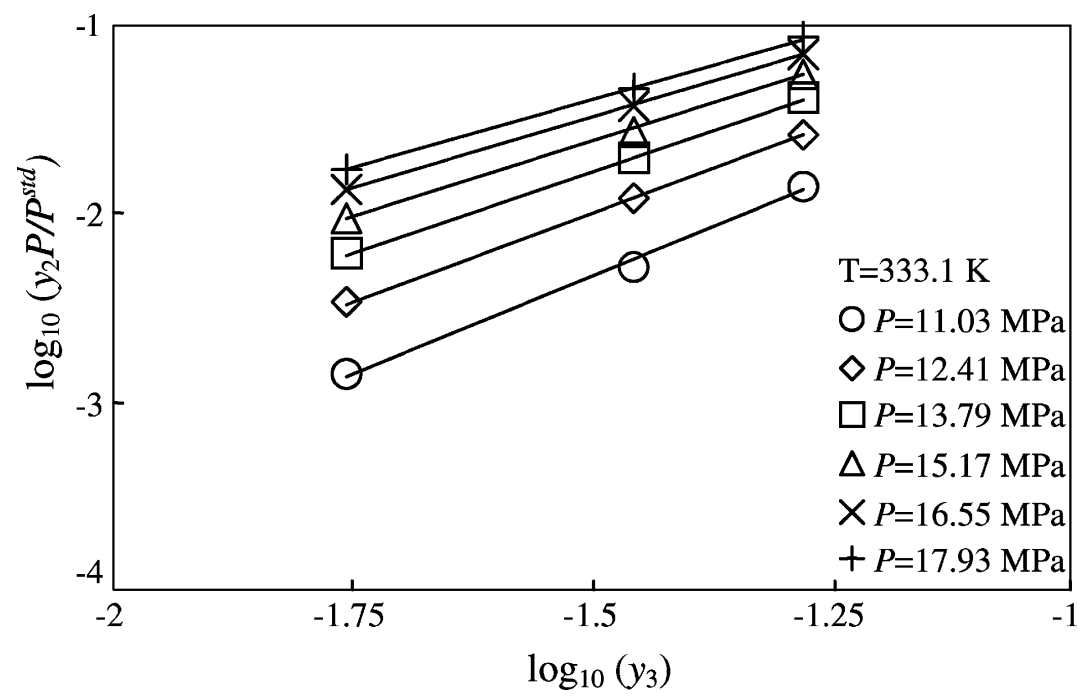

Fig. 3. $\log _{10}\left(y_{2} P / P^{\text {std }}\right)$ vs. $\log _{10}\left(y_{3}\right)$ for naproxen solubility data with ethanol as cosolvent at $333.1 \mathrm{~K}$ (data from [10]). 


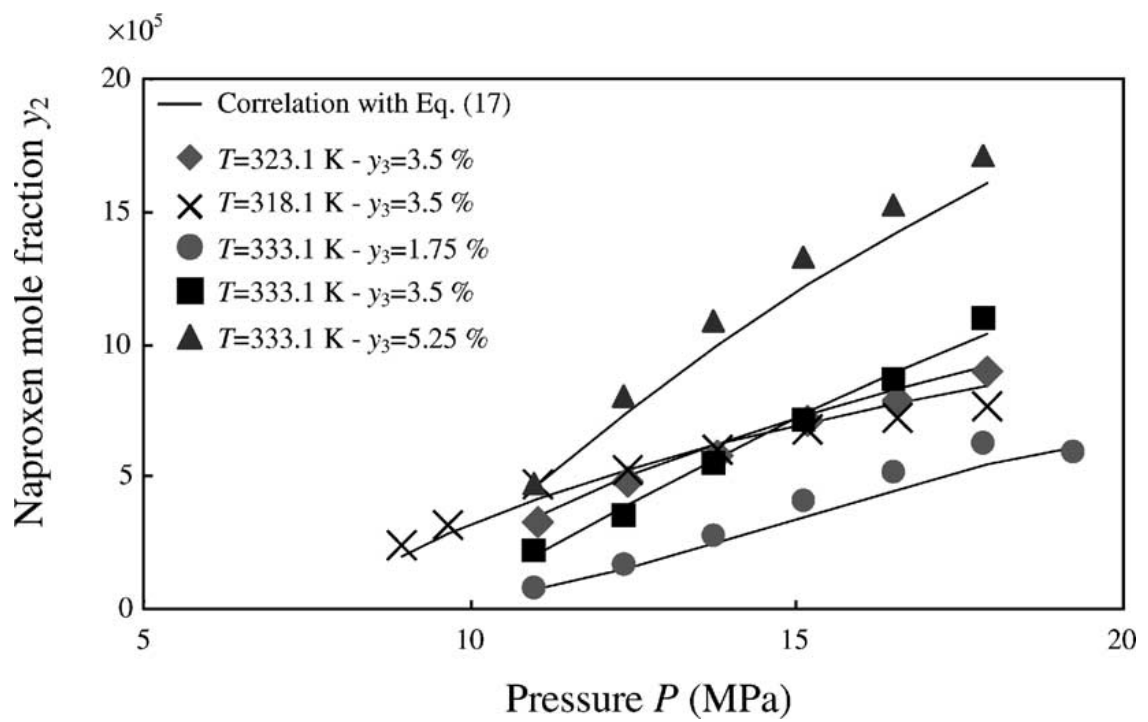

Fig. 4. Naproxen solubility vs. pressure with acetone as cosolvent: measurements and correlation with Eq. (17).

data with a cosolvent gives very good results (lines $2-5$ in Table 9). The maximum AAD is $7.2 \%$ for acetone for which there is the largest quantity of data, with a good representation of solubility data as shown on Fig. 4. Contrary to what has previously been observed for PC, the parameter $\eta_{4}$ is practically constant for all cosolvent-solvent mixtures, at about 0.33 , while $v_{4}$ depends on cosolvent. This value of $v_{4}$ allows classifying cosolvents by increasing cosolvent effect, in the same order as that experimentally observed [10].

The second model applied to naproxen solubility data is the Eq. (7). At first, it is applied to all data in pure $\mathrm{CO}_{2}$. A good correlation is obtained, as can be seen in the first line of Table 10. Then data for

Table 10

Correlation of naproxen solubility data with Eqs. (7), (18) and (20)

\begin{tabular}{|c|c|c|c|c|c|c|}
\hline \multirow[t]{2}{*}{ Cosolvent } & \multirow[t]{2}{*}{ Number of data } & \multicolumn{5}{|l|}{ Eq. (18) } \\
\hline & & $A_{4}(\mathrm{~K})$ & $B_{4}\left(\mathrm{~K} \mathrm{~m}^{3} \mathrm{~kg}^{-1}\right)$ & $C_{4}$ & $D_{4}(\mathrm{~K})$ & $\operatorname{AAD}(\%)^{\mathrm{a}}$ \\
\hline- & 18 & $-9.75^{\mathrm{b}}$ & $2.80^{\mathrm{c}}$ & $18.48^{\mathrm{d}}$ & - & 5.3 \\
\hline Ethanol & 24 & -10.00 & 2.80 & 19.68 & 12.30 & 8.7 \\
\hline Ethyl acetate & 18 & -6.42 & 3.15 & 7.82 & 7.46 & 4.0 \\
\hline Acetone & 33 & -9.19 & 2.85 & 16.77 & 8.23 & 6.9 \\
\hline Methanol & 26 & -8.60 & 3.05 & 14.98 & 11.27 & 11.0 \\
\hline Ethanol & 42 & -10.23 & 2.78 & 20.06 & 15.25 & 11.4 \\
\hline Ethyl acetate & 36 & -9.84 & 2.90 & 18.56 & 7.36 & 5.9 \\
\hline Acetone & 51 & -9.51 & 2.82 & 17.73 & 9.10 & 6.77 \\
\hline Methanol & 44 & -9.95 & 2.93 & 18.91 & 14.58 & 13.9 \\
\hline All & 119 & $-9.83^{\mathrm{e}}$ & $2.90^{\mathrm{f}}$ & $18.61^{\mathrm{g}}$ & $15.22^{\mathrm{h}}, 6.58^{\mathrm{i}}, 8.36^{\mathrm{j}}, 14.39^{\mathrm{k}}$ & 11.2 \\
\hline
\end{tabular}

${ }^{\mathrm{a}}$ Defined in Eq. (9). ${ }^{\mathrm{b}, \mathrm{c}, \mathrm{d}}$ coefficients $A_{2}, B_{2}$ and $C_{2}$ from Eq. (7); ${ }^{\mathrm{e}, \mathrm{f}, \mathrm{g}, \mathrm{h}, \mathrm{i}, \mathrm{j}, \mathrm{k}}$ coefficients $A_{6}, B_{6}, C_{6}, D_{6}, E_{6}, F_{6}$ and $G_{6}$, respectively, from Eq. (20). 


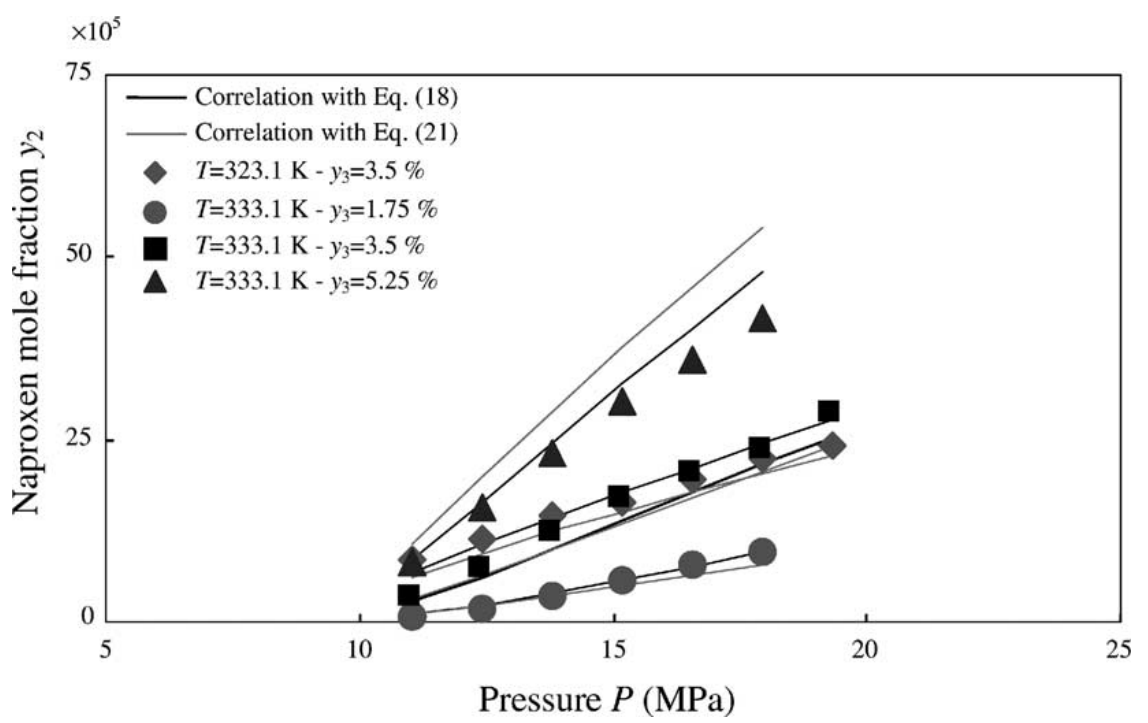

Fig. 5. Naproxen solubility vs. pressure with methanol as cosolvent: measurements and correlation with Eqs. (18) and (21).

each cosolvent are treated independently with Eq. (18) (lines 2-5 in Table 10). The maximum AAD is $11 \%$ for methanol, with a good representation of solubility data as illustrated on Fig. 5. As observed for PC data, parameters attributed to density, $B_{4}$, and to temperature, $C_{4}$, seem to be nearly constant and close to that obtained for pure $\mathrm{CO}_{2}$, except for ethyl acetate for which data exist at only one temperature. Thus, a correlation with Eq. (18) is carried out by gathering data for each cosolvent with the ones in pure $\mathrm{CO}_{2}$ (lines 6-9 in Table 10). This global treatment does not lead to a significant increase in the AAD, parameters $A_{4}, B_{4}$ and $C_{4}$ being the same for both $\mathrm{CO}_{2}$ used alone or mixed with a cosolvent. Then, these

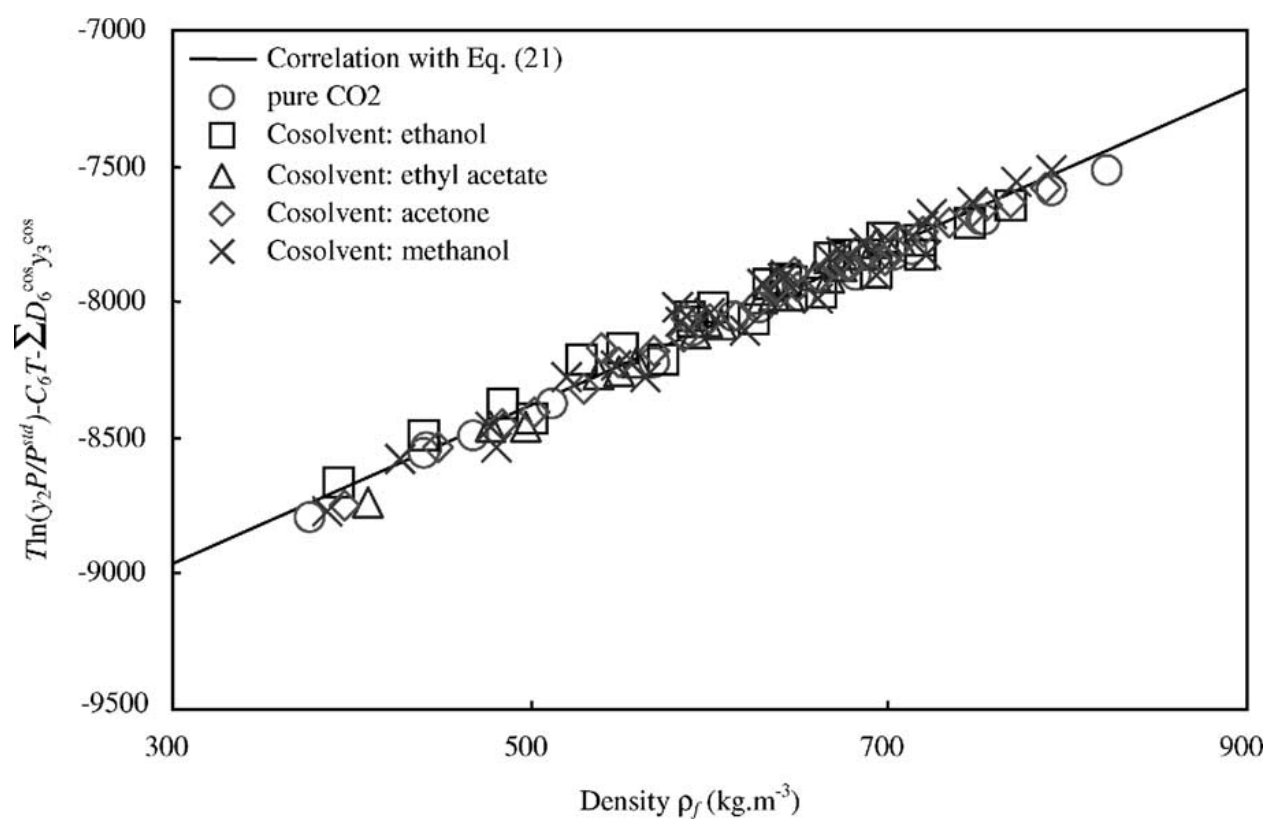

Fig. 6. $T \ln \left(y_{2} P / P^{\mathrm{std}}\right)-C_{6} T-\sum_{\cos } D_{6}^{\cos } y_{3}^{\cos }$ vs. $\rho_{\mathrm{f}}$ : naproxen experimental solubility data and correlation with Eq. (21). 
three coefficients can be considered as independent of the nature of the SCF. As previously observed for the pharmaceutical compound, it confirms that the part of cosolvent effect due to specific interactions is independent of density and temperature effects, and is quantified for each cosolvent by the value of $D_{4}$. Thus, the following relationship, similar to Eq. (19) with seven adjustable parameters can be applied:

$$
T \ln \left(\frac{y_{2} P}{P^{\text {std }}}\right)=A_{6}+B_{6} \rho_{\mathrm{f}}+C_{6} T+D_{6} y_{3}^{\text {ethanol }}+E_{6} y_{3}^{\text {ethyl acetate }}+F_{6} y_{3}^{\text {acetone }}+G_{6} y_{3}^{\text {methanol }} .
$$

The AAD obtained is equal to $11.2 \%$ with 119 data and four cosolvents treated. The good fit is illustrated for acetone as cosolvent on Fig. 5. This confirms the validity of this relationship, which can be written in a more general way as:

$$
T \ln \left(\frac{y_{2} P}{P^{\mathrm{std}}}\right)=A_{6}+B_{6} \rho_{\mathrm{f}}+C_{6} T+\sum_{\cos } D_{6}^{\cos } y_{3}^{\cos }
$$

where superscript cos means cosolvent. By plotting $T \ln \left(y_{2} P / P^{\mathrm{std}}\right)-C_{6} T+\sum_{\mathrm{cos}} D_{6}^{\cos } y_{3}^{\cos }$ versus $\rho_{\mathrm{f}}$, the 119 solubility data are gathered on a single line (Fig. 6).

\section{Discussion}

The application of the models to data in pure $\mathrm{CO}_{2}$ provides three relationships between $C_{2}, P$ and $T$ or $y_{2}, P$ and $T$ with, for given solute and solvent, constant values of three adjustable parameters. Finally, relationships obtained allow the prediction of the solubility $y_{2}$ in other operating conditions.

If a cosolvent is used, the extension of the Chrastil model can be applied only to mixtures at constant composition. On the contrary, the two other models provide two relationships between $y_{2}, P, T$ and $y_{3}$ which can be used for the calculation of the solubility under other experimental conditions, whatever the pressure, the temperature and the cosolvent mole fraction. The modified Ziger and Eckert model requires the use of a set of parameters for each cosolvent. The generalized Mendez-Santiago and Teja model allows the characterization of the solubility of a given solute in a given solvent with only one relationship for several cosolvents.

It is not possible to state a priori which model is the best among the three models described here. They are semi-empirical and it is recommended that they be tested in each individual case. In addition, it seems interesting to apply at least two of them to the same data in order to compare and to check the results obtained.

\section{Conclusion}

Solubility data for pharmaceutical solid have been correlated by means of three density-based semiempirical models: the Chrastil model, the Ziger and Eckert model and the Mendez-Santiago and Teja model.

The Ziger and Eckert model has been modified to be applicable when the saturated vapor pressure of the solute is unknown. The application of the three correlations to the data in pure $\mathrm{CO}_{2}$ leads to expressions which can be used for prediction purposes in a large range of pressure-temperature conditions.

In addition, the Chrastil and the Ziger and Eckert models have been extended to be applicable to solvent-cosolvent mixtures considered as pure SCF compounds. This work has confirmed the importance 
of specific interactions in the cosolvent effect. Based on experimental observations, a term has been introduced in the modified Ziger and Eckert model to represent the influence of the solvent-cosolvent composition. This novel relationship has allowed a good representation of all data for each cosolvent in supercritical $\mathrm{CO}_{2}$. The representation of all the data with two different cosolvents has been carried out with only one relationship by using a generalized Mendez-Santiago and Teja model, in which effects of density, temperature and cosolvent composition are quantified.

Finally, the validity of the relationships proposed in this work has been checked with naproxen solubility data in supercritical $\mathrm{CO}_{2}$. A good representation has been found with the modified Ziger and Eckert model for all of the four cosolvents studied. The generalized Mendez-Santiago and Teja model has allowed the correlation of 119 data with four different cosolvents by using only one equation with seven adjustable parameters.

List of symbols
$a$
$A_{1}, B_{1}$
$A_{1}^{\prime}, B_{1}^{\prime}, C_{1}^{\prime}$
$A_{2}, B_{2}, C_{2}$
$A_{3}, B_{3}, D_{3}$
$A_{4}, B_{4}, C_{4}, D_{4}$
$A_{5}, B_{5}, C_{5}, D_{5}, E_{5}$
$A_{6}, B_{6}, C_{6}, D_{6}, E_{6}, F_{6}, G_{6}$
$\mathrm{AAD}$
$C$
$E$
$E o S$
$i, j$
$k$
$k_{1}, k_{3}$
$k_{i j}$
$l_{i j}$
$M$
$n$
$P$
$R$
$T$
$v$
$y$

Greek letters

$\alpha, \beta$

$\delta$

$\Delta$

$\varepsilon_{2}$

$\eta_{1}, v_{1}$ energy parameter in vdW equation $\left(\mathrm{J} \mathrm{m}^{3} \mathrm{~mol}^{-2}\right)$

coefficients in Eq. (4) $\left(\mathrm{K}, \mathrm{K} \mathrm{m}^{3} \mathrm{~kg}^{-1}\right)$

coefficients in Eq. (5) $\left(\mathrm{Pa} \mathrm{K}, \mathrm{K} \mathrm{m}^{2} \mathrm{~s}^{-2}, \mathrm{~Pa}\right)$

coefficients in Eq. (7) $\left(\mathrm{K}, \mathrm{K} \mathrm{m}^{3} \mathrm{~kg}^{-1},-\right)$

coefficients in Eq. (8) $\left(\mathrm{K}, \mathrm{K} \mathrm{m}^{3} \mathrm{~kg}^{-1}, \mathrm{~K}\right)$

coefficients in Eq. (18) $\left(\mathrm{K}, \mathrm{K} \mathrm{m}^{3} \mathrm{~kg}^{-1},-, \mathrm{K}\right)$

coefficients in Eq. (19) $\left(\mathrm{K}, \mathrm{K} \mathrm{m}^{3} \mathrm{~kg}^{-1},-, \mathrm{K}, \mathrm{K}\right)$

coefficients in Eq. (20) $\left(\mathrm{K}, \mathrm{K} \mathrm{m}^{3} \mathrm{~kg}^{-1},-, \mathrm{K}, \mathrm{K}, \mathrm{K}, \mathrm{K}\right)$

average absolute deviation, defined in Eq. (9)

concentration $\left(\mathrm{kg} \mathrm{m}^{-3}\right)$

solubility enhancement factor, defined in Eq. (3)

equation of state

coefficients in Eq. (6) $(-, \mathrm{K})$

association number in Eq. (1)

association numbers in Eq. (10)

binary interaction parameter

binary interaction parameter

molecular weight $\left(\mathrm{kg} \mathrm{mol}^{-1}\right)$

number of data

pressure $(\mathrm{Pa})$

universal gas constant $\left(\mathrm{J} \mathrm{mol}^{-1} \mathrm{~K}^{-1}\right)$

temperature $(\mathrm{K})$

mole volume $\left(\mathrm{cm}^{3} \mathrm{~mol}^{-1}\right)$

mole fraction

coefficients in Eq. (1) $(\mathrm{K},-)$

Hildebrand solubility parameter $\left(\mathrm{Pa}^{1 / 2}\right)$

ratio of solubility parameter, defined in Eq. (3)

dimensionless energy parameter, defined in Eq. (3)

coefficients in Eq. (2) 


$$
\begin{aligned}
& \eta_{2}, \kappa_{2}, \nu_{2} \\
& \eta_{3}, \kappa_{3}, \nu_{3} \\
& \eta_{4}, \kappa_{4}, \lambda_{4}, \nu_{3} \\
& \rho \\
& \omega
\end{aligned}
$$

\section{Subscripts}

1

2

3

$\mathrm{C}$

cal

$\exp$

$\mathrm{f}$

$\mathrm{m}$

\section{Superscripts}

sat

std

$\mathrm{L}$ coefficients in Eq. (13) $(-, \mathrm{K},-)$

coefficients in Eq. (14) $(-, \mathrm{K},-)$

coefficients in Eq. (17) $(-, \mathrm{K},-,-)$

density $\left(\mathrm{kg} \mathrm{m}^{-3}\right)$

acentric factor

light solvent component (carbon dioxide)

heavy solute component (solid)

cosolvent

critical point

calculated value

experimental value

supercritical phase

solvent-cosolvent mixture

sublimation

standard

liquid

\section{Acknowledgements}

The authors would like to acknowledge the financial and technical support of the Pierre Fabre Research Institute (IRPF).

\section{References}

[1] M. Sauceau, D. Richon, J.-J. Letourneau, J. Fages, in: K. Mallikarjunan, G. Barbosa-Canovas (Eds.), Proceedings of the AIChE Annual Meeting \& 7th Conference of Food Engineering, AIChE Publication No. 151, Reno, 2001, pp. $212-217$.

[2] M. Sauceau, J. Fages, J.-J. Letourneau, D. Richon, Ind. Eng. Chem. Res. 39 (2000) 4609-4614.

[3] J. Chrastil, J. Phys. Chem. 86 (1982) 3016-3021.

[4] D. Ziger, C. Eckert, Ind. Eng. Chem. Process Des. Dev. 22 (1983) 582-588.

[5] A. Harvey, J. Phys. Chem. 94 (1990) 8403-8406.

[6] J. Mendez-Santiago, A. Teja, Fluid Phase Equilib. 158-160 (1999) 501-510.

[7] J. Mendez-Santiago, A. Teja, Ind. Eng. Chem. Res. 39 (2000) 4767-4771.

[8] D.-Y. Peng, D. Robinson, Ind. Eng. Chem. Fundam. 15 (1976) 59-64.

[9] A. Kordikowski, A.P. Schenk, R.M. Van Nielen, C.J. Peters, J. Supercrit. Fluids 8 (1995) 205-216.

[10] S. Ting, S. Macnaughton, D. Tomasko, N. Foster, Ind. Eng. Chem. Res. 32 (1993) 1471-1481.

[11] C.J. Giddings, M.N. Myers, J.W. King, J. Chromatogr. Sci. 7 (1969) 276-283.

[12] G. Gurdial, N. Foster, Ind. Eng. Chem. Res. 30 (1991) 575-580.

[13] R. Fedors, Polym. Eng. Sci. 14 (1979) 147-154. 